\title{
Living Alone with Mild-To-Moderate Dementia: Findings from the IDEAL Cohort
}

\author{
Linda Clare $^{\mathrm{a}, *}$, Anthony Martyr ${ }^{\mathrm{a}}$, Catherine Henderson $^{\mathrm{b}}$, Laura Gamble $^{\mathrm{c}}$, Fiona E. Matthews ${ }^{\mathrm{c}}$, \\ Catherine Quinn $^{\mathrm{d}}$, Sharon M. Nelis ${ }^{\mathrm{a}}$, Jennifer Rusted ${ }^{\mathrm{e}}$, Jeanette Thom ${ }^{\mathrm{f}}$, Martin Knapp ${ }^{\mathrm{b}}$, \\ Nicola Hart ${ }^{\mathrm{g}}$ and Christina Victor ${ }^{\mathrm{h}}$ \\ ${ }^{a}$ REACH: The Centre for Research in Ageing and Cognitive Health, College of Medicine and Health, \\ University of Exeter, St Luke's Campus, Exeter, UK \\ ${ }^{\mathrm{b}}$ Personal Social Services Research Unit, London School of Economics and Political Science, London, UK \\ ${ }^{\mathrm{c}}$ Institute for Health and Society, Newcastle University, Newcastle, UK \\ ${ }^{\mathrm{d}}$ Centre for Applied Dementia Studies, University of Bradford, Bradford, UK \\ ${ }^{\mathrm{e}}$ School of Psychology, University of Sussex, Brighton, UK \\ ${ }^{\mathrm{f}}$ School of Medical Sciences, University of New South Wales, Sydney, Australia \\ ${ }^{\mathrm{g}}$ Research Development and Evaluation, Alzheimer's Society, London, UK \\ ${ }^{\mathrm{h}}$ College of Health and Life Sciences, Brunel University London, London, UK
}

Accepted 17 September 2020

\begin{abstract}
.
Background: A significant proportion of people with dementia live alone, but little is known about their specific needs.

Objective: To understand the profile of people living alone with mild-to-moderate dementia in the UK and identify any systematic differences associated with living situation.

Methods: We analyzed cross-sectional data from 1,541 people with mild-to-moderate dementia and 1,277 caregivers participating in the IDEAL cohort at the first wave of assessment.

Results: There were 1,256 (81.5\%) people with dementia living with others and $285(18.5 \%)$ living alone, of whom 51 (3\% of whole sample) reported little or no informal support. There were relatively few differences associated with living situation and odds ratios were generally small. People living alone were older on average, and more likely to be female, than those living with others. Those living alone were more likely to have higher cognitive ability and self-reported functional ability, and more social contact with those from other households. They were also lonelier, expressed less satisfaction with life, and used home care services and equipment more. There were no differences in symptoms, mood, quality of life, or well-being. Conclusion: The findings support the view that it is possible to 'live well' with mild-to-moderate dementia while living alone, given appropriate support, including home care and equipment. Nevertheless, it is important to consider how those living alone may be supported to have a more satisfactory experience, and how health and social care services can best respond to their needs.
\end{abstract}

Keywords: Aids and adaptations, Alzheimer's disease, service use, social capitals, assets and resources, vascular dementia

\footnotetext{
${ }^{*}$ Correspondence to: Professor Linda Clare, Centre for Research in Ageing and Cognitive Health, College of Medicine and Health, University of Exeter, Exeter EX1 2LU, UK. Tel.: +44 0 1392 726229; E-mail: 1.clare@exeter.ac.uk.; ORCID ID: 00000003-3989-5318
}

\section{INTRODUCTION}

Social trends toward increasing numbers of people living alone in later life may point to future increases in the proportion of people with early-stage dementia living alone in the community [1]. People living alone with dementia may be at higher risk of adverse events and outcomes than those living with others, yet we 
know relatively little about their specific needs or how to provide care effectively [2].

Evidence from European and North American samples suggests that the proportion of people with dementia living alone lies somewhere between $28 \%$ and $51 \%$ [2-4]. As different recruitment strategies and inclusion criteria influence the proportion of people living alone who take part in research studies, figures from such studies may not be representative of the population as a whole. One early study based on medical records provided a lower estimate of $19 \%$ [5].

Living alone does not necessarily mean that people are unsupported through their informal social networks. Many of those living alone will still have access in varying degrees to help and support from family members or close friends, whether near at hand or further away. However, some have no such support. In a Canadian study, $31.5 \%$ lived alone and $4 \%$ said they had no-one they could count on for help [6]; in a more recent German study, 51\% lived alone and $9 \%$ had no informal caregiver providing support [4]. These people constitute a particularly vulnerable group, and are likely to be admitted to residential care sooner than those who have at least some support from an available caregiver [7].

People with dementia living alone may sometimes have difficulty recognizing their own limitations or needs for help, and are at increased risk of numerous adverse outcomes, including social isolation, exploitation, accidental injury, malnutrition, and selfneglect [2]. A cross-sectional study in the UK found that people with dementia living alone were more likely to experience psychological distress, and more vulnerable to accidental self-harm, than those living with others [8]. A prospective study following 211 people with early-stage dementia living alone over one year in Canada found that $10 \%$ (22) experienced a significant harm during that period, such as significant injury, damage to property, or negative effects of self-neglect or disorientation [9].

The experience of living alone with the cognitive and functional impairments resulting from dementia has been explored in several qualitative studies and notably described as a 'vague existence' [10]. These reports suggest that the experience is characterized by difficulty managing the home, finances, and everyday tasks, difficulty getting out and about and navigating public spaces, and difficulty in keeping oneself entertained; the result is isolation, loneliness, boredom, and a lack of purpose and meaning in life [10-12]. In addition, some participants described negative experiences with services and individual care workers $[11,12]$. However, people with dementia in this situation draw on their personal resources, rich inner lives, and desire for meaningful connection to find ways of coping [13].

Living alone with early-stage dementia is likely to be a growing phenomenon, presents challenges for coping, and may result in higher levels of risk and unmet need and poor-quality experience in everyday life, especially for those with little or no support from family or friends. Understanding more about the profile and needs of people living alone with dementia is important to help shape future policy and practice in this area [2]. In the current study, we draw on data from the IDEAL cohort $[14,15]$ to better understand the profile of people living alone with mild-to-moderate dementia in the UK and to explore, across a range of indicators, whether there are systematic differences between those living alone and those living with others. In particular, we aim to identify any differences that might be amenable to, or point to new possibilities for, intervention at either individual or community levels.

\section{METHODS}

\section{Design}

We analyzed cross-sectional data from 1,541 people with mild-to-moderate dementia (of any type) and 1,137 caregivers participating in the IDEAL longitudinal cohort study $[14,15]$ at the first wave of assessment. The analyses are based on version 4 of the IDEAL T1 dataset. IDEAL was approved by Wales Research Ethics Committee 5 (reference 13/WA/0405) and the Ethics Committee of the School of Psychology, Bangor University (reference 2014 11684). IDEAL is registered with the UK Clinical Research Network (UKCRN), number 16593.

\section{Participants}

IDEAL participants were recruited through memory services and other specialist clinics within the UK National Health Service (NHS), and via the online Join Dementia Research portal, between July 2014 and August 2016. Inclusion criteria were a clinical diagnosis of dementia, a Mini-Mental State Examination (MMSE) [16] score of 15 or above indicating mild-to-moderate severity, and residing in the community. Exclusion criteria were inability to provide informed consent, terminal illness, and 
any known potential for home visits to pose a risk to researchers. Where possible a family member or close friend (here referred to as a 'caregiver') was recruited to participate alongside the person with dementia, and provided informant ratings on relevant measures. For the first wave of assessment in this longitudinal cohort study, participants were visited by researchers on 3 occasions; people with dementia completed the questionnaires in face-to-face interviews with the researcher, while caregivers were given their questionnaires to complete by themselves while the researcher was interviewing the person with dementia. The cohort at Time 1 comprised 1,547 people with dementia, of whom 1,283 also had a family member or close friend involved [17, 18]. Information about living situation was available for all but 6 of the participants with dementia.

\section{Measures}

\section{Personal characteristics and demographic information}

We recorded age, sex, educational qualifications, and dementia diagnosis, and calculated socioeconomic status on the basis of Office for National Statistics [19] classifications. The Charlson Comorbidity Index [20,21] was used to identify number of co-morbid conditions in addition to dementia, which was excluded from the Index, and participants gave a subjective rating of their own health over the past 4 weeks on a 6 point scale from 'very poor' to 'excellent' [22].

\section{Cognitive and functional ability and other symptoms}

Cognitive function was assessed with the MMSE and the Addenbrooke's Cognitive Examination-III (ACE-III) [23]. Dependence was assessed with the Dependence Scale [24] and functional ability with the modified 11-item Functional Activities Questionnaire $[25,26]$, in both self-rated and where possible informant-rated versions. Depression was assessed through self-report on the 10-item Geriatric Depression Scale [27] recoded into a binary depressed (4-10)/not depressed (0-3) variable [28]. Neuropsychiatric symptoms were rated by caregivers where available using the Neuropsychiatric Inventory Questionnaire [29, 30].

\section{Psychological characteristics}

Self-esteem was assessed with the Rosenberg SelfEsteem Scale [31], self-efficacy with the Generalized
Self-Efficacy Scale [32], optimism with the six nonfiller items from the Life Orientation Test-Revised [33], and loneliness with the 6-item version of the De Jong Gierveld Loneliness Scale $[34,35]$ recoded into a binary lonely (2-6)/not lonely $(0-1)$ variable $[35,36]$. We assessed perceived stigma with 4 questions from the Stigma Impact Scale for people with dementia [37]; these questions were only administered to participants showing awareness of having dementia based on responses to the screening items of the Representations and Adjustment to Dementia Index [38].

\section{Social capitals, assets, and resources}

Social network size was measured with selfand informant ratings on the 6-item Lubben Social Network Scale [39]. Access to social resources within these social networks was measured with the Resource Generator UK [40]; for the purposes of the present study, as questions about employment were not relevant for the majority of participants with dementia, some questions were removed when calculating the total score. Social capital was measured using the core social capital items from the Office for National Statistics [41]: neighborhood reciprocity and trust, neighborhood social problems, civic participation, social participation, and frequency of social contact with people not living in the same household. Civic and social participation were coded as $0=$ no participation, $1=$ some participation, and $2+=$ extensive participation. Neighborhood reciprocity and trust (gauged by asking the participant to estimate the likelihood of a lost purse or wallet being returned with nothing missing) was recoded into a binary likely (4-5)/other (1-3) variable. Cultural capital was assessed with self- and informant ratings of frequency of engagement in 13 activities such as going to the opera, playing bingo, visiting stately homes, eating out, etc., taken from the Cultural Capital and Social Exclusion Survey [42].

\section{Indices of 'living well'}

Quality of life was assessed with the Quality of Life in Alzheimer's Disease scale (QoL-AD) [43], life satisfaction with the Satisfaction with Life Scale [44], and well-being with the World Health OrganizationFive Well-Being Index [45].

\section{Service use}

Methods of collecting and costing data on service use are described in detail in Henderson et al. [46]. Here we consider use of paid health 
and care services, medications, and equipment and adaptations. A four-category variable describing the purpose of equipment and adaptations was created to explore whether their use differed by living arrangement: 1) memory aids (calendar clocks, medication dispenser reminders); 2) falls technology (pendant and falls alarms); 3) activities of daily living equipment (bath seats, bed rails, commodes, over bath showers, incontinence pads, walk-in showers, toilet seats, perching stools); and 4) mobility equipment (grab/stair rails, outdoor rails, sticks, frames).

Further details about the measures listed above can be found in the IDEAL study protocol and subsequent publications [14, 17].

\section{Statistical analysis}

Participants with dementia were classified as living alone or living with others. Among those who were living alone, we identified a sub-group receiving little or no support from others (living alone with low support). These were individuals who 1) had no caregiver participating in the study, 2) said they received no help at all or less than one hour of help from family or friends in the past week, and 3) if the response to the previous question was missing, indicated in response to an earlier question that they had received no help from others for any of the following specific support needs in the past week: personal care; finances; housework or laundry; attending appointments; medication; safety; other.

Individuals living alone could have widely varying levels of support from others, and those who live alone with little or no support might be considered potentially most vulnerable. Therefore, in the analyses that follow, we considered 1) all those living alone, and 2) those living alone with low support. We used chi-square tests, ANOVA, and logistic regression to explore differences between these groups and the larger group of participants who lived with others, usually a spouse or partner. For analyses of service use, which only considered all those living alone, predictive margins and contrasts of predictive margins were also calculated. Holm-Bonferroni correction was applied to all analyses, and we report only findings that remained significant after correction.

\section{RESULTS}

Of the 1,541 participants with dementia included in this analysis, 285 (18.5\%) lived alone and 1,256 lived with others; 1,165 (75.6\%) lived with a spouse or partner and 91 (5.9\%) lived with someone other than a spouse or partner. Of those living with others, $1,137(90.5 \%)$ had a caregiver taking part in the study.

Just over half of the 285 individuals living alone had no caregiver participating in the study (145, $50.9 \%$ ) while the remaining 140 had a caregiver contributing information. Of those with no caregiver contributing, $51(35 \%)$ specifically indicated they had received no help or less than one hour of help during the past week. Information about the extent of help received was missing for 38 of those living alone. Among the rest, the majority received either 1-4 hours of help (42.6\%) or 5-8 hours of help (29.6\%).

\section{Personal and demographic characteristics}

Personal and demographic characteristics, together with information about dementia diagnoses and health, are summarized in Supplementary Table 1. More than two-thirds of those living alone were female $(67.7 \%)$ while nearly two-thirds of those living with others were male $(61.8 \%) ; \chi^{2}(1)$, $82.19, p<0.001$. The majority of those living alone were widowed $(194,68.1 \%)$; the remainder were divorced $(62,21.8 \%)$ or single $(19,6.7 \%)$. On average, those living alone were significantly older than those living with others (79.88 years versus 75.57 years; $F(1,1539)=61.49, p<0.001)$. There was a significant difference in socio-economic status as the distribution across categories varied somewhat between the two groups with no clear pattern $\left(\chi^{2}(1)\right.$, 18.64, $p=0.005)$, but no significant difference in educational level $\left(\chi^{2}(3), 6.68, p=0.083\right)$. There was no clear pattern of differences due to dementia diagnosis, although the proportion of people with mixed Alzheimer's and vascular dementia was higher among those living alone $(80,28.1 \%$ versus $246,19.6 \%$ ) while the proportion of people with rare dementias (frontotemporal dementia, Parkinson's disease dementia, dementia with Lewy bodies, and other rare dementias) was lower $\left(\chi^{2}(1), 23.62\right.$, $p=0.001)$. Neither number of co-morbid health conditions nor subjective ratings of health differed significantly between the groups after controlling for age, socio-economic status, and dementia diagnosis. Based on these initial analyses, age, sex, socio-economic status, and dementia diagnosis were included as covariates in subsequent analyses comparing all those living alone and all those living with others in the domains of cognitive and functional ability and other symptoms, psychological characteristics, social capitals, assets, and resources, 
Table 1

Logistic regression analysis of the associations of cognition, functional ability, psychological characteristics, social resources, subjective health, and indices of living well, with living situation

\begin{tabular}{|c|c|c|}
\hline Measure & $\begin{array}{l}\text { Living alone }(n=285) \text { versus } \\
\text { living with others }(n=1,256)^{+}\end{array}$ & $\begin{array}{c}\text { Living alone with low support } \\
(n=51) \text { versus living } \\
\text { with others }(n=1,256)^{\dagger}\end{array}$ \\
\hline Mini-Mental State Examination & OR $1.08(1.04,1.13), \boldsymbol{p}<\mathbf{0 . 0 0 1}$ & OR $1.18(1.08,1.28), \boldsymbol{p}<\mathbf{0 . 0 0 1}$ \\
\hline \multicolumn{3}{|l|}{ Addenbrooke's Cognitive Examination-III } \\
\hline Attention & OR $1.14(1.08,1.20), \boldsymbol{p}<\mathbf{0 . 0 0 1}$ & OR $1.22(1.09,1.37), \boldsymbol{p}<\mathbf{0 . 0 0 1}$ \\
\hline Fluency & OR $1.10(1.04,1.15), \boldsymbol{p}<\mathbf{0 . 0 0 1}$ & OR $1.18(1.07,1.31), \boldsymbol{p}=\mathbf{0 . 0 0 1}$ \\
\hline Memory & OR $1.04(1.01,1.07), p=0.014$ & \\
\hline Visuospatial & OR $1.06(1.01,1.12), p=0.016$ & \\
\hline Total score & OR $1.03(1.01,1.04), \boldsymbol{p}<\mathbf{0 . 0 0 1}$ & OR $1.04(1.01,1.06), \boldsymbol{p}=\mathbf{0 . 0 0 2}$ \\
\hline Dependence Scale-S & OR $0.86(0.81,0.92), \boldsymbol{p}<\mathbf{0 . 0 0 1}$ & OR $0.64(0.53,0.76), \boldsymbol{p}<\mathbf{0 . 0 0 1}$ \\
\hline Dependence Scale-I & OR $0.90(0.83,0.98), p=0.011$ & - \\
\hline Functional Activities Questionnaire-S & OR $0.96(0.94,0.98), \boldsymbol{p}<\mathbf{0 . 0 0 1}$ & OR $0.85(0.80,0.91), \boldsymbol{p}<\mathbf{0 . 0 0 1}$ \\
\hline Functional Activities Questionnaire-I & OR $0.97(0.94,0.99), p=0.007$ & \\
\hline Depressed & OR $1.38(1.01,1.89), p=0.042$ & \\
\hline Lonely & OR $2.11(1.56,2.84), \boldsymbol{p}<\mathbf{0 . 0 0 1}$ & OR $2.11(1.19,3.75), p=0.011$ \\
\hline Lubben Social Network Scale-I & OR $0.93(0.89,0.97), \boldsymbol{p}=\mathbf{0 . 0 0 1}$ & - \\
\hline ONS Social participation & & OR $1.40(1.00,1.96), p=0.048$ \\
\hline Frequency of social contact & OR $1.16(1.11,1.22), \boldsymbol{p}<\mathbf{0 . 0 0 1}$ & \\
\hline Cultural Capital-S & OR $0.97(0.94,1.00), p=0.020$ & \\
\hline Self-rated health & OR $0.84(0.73,0.95), p=0.007$ & \\
\hline Quality of Life in Alzheimer's Disease & OR $0.97(0.94,0.99), p=0.018$ & \\
\hline Satisfaction with Life Scale & OR $0.92(0.90,0.94), \boldsymbol{p}<\mathbf{0 . 0 0 1}$ & OR $0.89(0.86,0.93), \boldsymbol{p}<\mathbf{0 . 0 0 1}$ \\
\hline World Health Organization-Five Well-Being Index & OR $0.99(0.98,1.00), p=0.009$ & \\
\hline
\end{tabular}

and indices of 'living well'. We modelled the impact of living alone on service use controlling for age, sex, socio-economic status, and dementia diagnosis.

Those living alone with low support $(n=51) \mathrm{did}$ not differ significantly from those living with others in age, socio-economic status, or dementia diagnosis. Gender composition followed the same pattern as seen in the wider group $\left(\chi^{2}(1), 10.48, p=0.001\right)$. Therefore, when making further comparisons for this sub-group, we controlled for sex only.

Results of logistic regression analyses of the associations of cognition, functional ability, psychological characteristics, social resources, subjective health, and indices of living well with living situation are summarized in Table 1.

\section{Cognitive and functional ability and other symptoms}

Scores for cognitive and functional ability and other symptoms are summarized in Supplementary Table 2. People with higher MMSE and ACE-III scores, and those who by their own report were less dependent and had fewer functional difficulties, were more likely to live alone (see Table 1). However, for individuals with a caregiver participating, informant ratings on these measures did not discriminate between those living alone and those living with others. The presence of depression or other neuropsychiatric symptoms was not associated with living situation. The pattern of results was the same where data were available for those living alone with low support $(n=51)$; see Table 1 .

\section{Psychological characteristics}

Scores on measures of psychological characteristics are shown in Supplementary Table 3. Overall, those with higher levels of loneliness were more likely to live alone (see Table 1), although levels of loneliness were low irrespective of living situation. Levels of self-esteem, self-efficacy, optimism, and perceived stigma were not associated with living situation. Considering just those living alone with low support $(n=51)$, feelings of loneliness, self-esteem, self-efficacy, optimism, and perceived stigma were not associated with living situation.

\section{Social capitals, assets, and resources}

Scores on measures of social capitals, assets, and resources are summarized in Supplementary Table 4. 
Overall, when social network size was rated by informants, people with smaller social networks were more likely to be living alone (see Table 1); however, as the mean difference in network size was small, this could simply reflect the fact that they were living alone rather than any difference in wider social networks. The difference in social network size did not emerge in self-ratings after correcting for multiple comparisons. In contrast, people reporting higher frequency of social contact with people not in the same household were more likely to be living alone. Neighborhood reciprocity and trust, social or civic participation, local problems, and self-rated or informant-rated cultural capital were not associated with living situation. Considering just those living alone with low support $(n=51)$, none of the measures of social capitals, assets and resources were associated with living situation.

\section{Indices of 'living well'}

Scores on measures of quality of life, satisfaction with life, and well-being are shown in Supplementary Table 6. Overall, people with lower scores for satisfaction with life were more likely to be living alone (see Table 1), but there were no differences in quality of life or well-being. This was the case both for all those living alone and for those living alone with low support.

\section{Service use}

The proportions of those living alone and those living with others using paid health and care services over the prior three months, and the proportions using equipment and adaptations, are given in Supplementary Tables 6 and 7 .

In both groups, office visits to the general medical practitioner (GP) were the most commonly used service (66\% living with others; $59 \%$ living alone). Use of GP home visits, home care, meals on wheels, and cleaners was higher in the living alone group, while use of practice nurses (who do not make home visits) was lower. Participants living alone in receipt of home care services had approximately seven times more visits on average than participants living with others. A greater proportion of participants living alone used equipment or adaptations of some kind than those living with others, and this was the case for all four specific categories: memory aids, falls technology, activities of daily living, and mobility equipment.
Table 2

Logistic regression analysis of the associations of service and equipment use over the previous 3 months with living situation

\begin{tabular}{lc}
\hline Service or equipment type & $\begin{array}{l}\text { Living alone }(n=285) \text { versus } \\
\text { living with others }(n=1,256)\end{array}$ \\
\hline General practitioner - home & OR $2.10(1.19,3.73), p=0.011$ \\
Home care & OR $4.44(2.99,6.61), \boldsymbol{p}<\mathbf{0 . 0 0 1}$ \\
Meals on wheels & OR $8.69(3.04,24.84), \boldsymbol{p}<\mathbf{0 . 0 0 1}$ \\
Cleaner & OR $1.68(1.20,2.35), p=0.003$ \\
Day center days & OR $1.53(1.01,2.31), p=0.044$ \\
Use of equipment & OR $2.05(1.43,2.96), \boldsymbol{p}<\mathbf{0 . 0 0 1}$ \\
Memory aids & OR $2.91(2.01,4.19), \boldsymbol{p}<\mathbf{0 . 0 0 1}$ \\
Fall prevention aids & OR $4.22(2.96,6.01), \boldsymbol{p}<\mathbf{0 . 0 0 1}$ \\
Activities of daily living aids & OR $1.63(1.20,2.21), \boldsymbol{p}=\mathbf{0 . 0 0 2}$ \\
Mobility aids & OR $1.47(1.08,2.00), p=0.014$ \\
\hline
\end{tabular}

Bold indicates significant at the $5 \%$ level after Holm-Bonferroni correction. Adjusted for age, sex, socio-economic status, dementia diagnosis.

People receiving home care and meals on wheels services, people using equipment of any kind, and people specifically using aids for memory, falls prevention, and activities of daily living were more likely to be living alone (Table 2). The odds of having home care and the odds of using aids for falls prevention were both about 4 times greater for people living alone than for people living with others.

Predicted probabilities of use, controlling for age, sex, socio-economic status, and diagnosis, were low for many services (Supplementary Figure 1). Contrasts of predictive margins suggested that people using a home care service had a $25 \%$ higher likelihood of living alone (contrast 0.25 ; 95\% CI: 0.17 , 0.32 ) and users of aids for falls prevention had a $23 \%$ higher likelihood of living alone (contrast $0.23 ; 95 \%$ CI 0.17, 0.23), than non-users.

\section{DISCUSSION}

Understanding more about the profile and needs of people living alone with dementia is important, but relatively little evidence is available to help shape policy and practice. This study contributes new evidence by drawing on data from a large cohort of people with a diagnosis of mild-to-moderate dementia recruited through NHS memory services in Great Britain to examine the characteristics of those living alone and identify any systematic differences between those living alone and those living with others. Comparison of personal and demographic characteristics, cognitive and functional ability, symptoms, psychological characteristics, social capitals, assets and resources, and perceptions of 'living well' yielded few differences. Overall, people living alone were older on 
average, and more likely to be female, than those living with others. Those with higher cognitive ability and self-reported functional ability, who reported more loneliness, more social contact with those from other households, and less satisfaction with life, and who used home care services and equipment such as falls prevention aids, were more likely to live alone. The only characteristics associated with greater likelihood of living alone with low support were higher cognitive and self-rated functional ability and lower satisfaction with life.

The proportion of people with dementia in the IDEAL cohort who were living alone was $18.5 \%$. This is lower than the range identified in the majority of studies [2], which is closer to one-third. Variations in sampling procedure and inclusion criteria may, to some extent, account for the differing proportions identified in different studies and it is noteworthy that an earlier US study based on a large sample of medical records rather than direct recruitment from clinical services [5] gave a similar proportion to our estimate which is based on participants recruited in 29 areas of Great Britain through the comprehensive publicly-funded health care system. The finding that around one-fifth of individuals with a diagnosis of mild-to-moderate dementia are living alone nonetheless demonstrates that this is a sizeable group of people whose needs require consideration.

In terms of personal and demographic characteristics, previous studies have found that people living alone with dementia include a preponderance of widowed women [3-6], and our findings were in line with this. Most studies have found that those living alone tend to be older than those living with others [3-5] although this is not a universal finding [6]. Our overall group of people living alone did tend to be older than those living with others, but this was not the case for the sub-group that were living alone with low support. This emphasizes the point that people living alone with dementia are not a single homogeneous group; rather, the reasons why people are living alone, and the viability of continuing to live alone, will differ for different individuals and groups, and a more finegrained approach is indicated when considering the support needs of those living alone.

Similarly, our findings indicate that in terms of cognition, functional ability, mood and neuropsychiatric symptoms there is no distinct profile that characterizes people living alone with mild-to-moderate dementia. We found few significant differences, and for those differences that remained significant after correction for multiple comparisons, the odds ratios were small. Findings from other studies are mixed. Some report differences in cognition $[5,6]$ while others do not $[3,4]$. Some report differences in functional ability $[6,47]$ and others do not $[3,4]$. No other studies have reported differences in depression $[4,47]$. Thus, people living alone with mild-to-moderate dementia can in general be considered not much different to those living with others in these domains; however, as dementia progresses, those who do not have an available caregiver may require more support to manage the impact of their symptoms on daily life.

The domain of social contact and social inclusion is a particular focus of the IDEAL program from which our data were drawn. We found few differences between those living alone and those living with others in this domain, and those differences identified were small. However, one important finding is that people living alone were significantly more likely to feel lonely than those living with others, despite being significantly more likely to have higher levels of social contact with people from outside the household. While it appears that people living alone with mild-to-moderate dementia are not particularly different to those living with others, it is probable that due to their circumstances they may benefit from support to reduce feelings of loneliness and ensure continued social inclusion.

While those living alone rated quality of life and well-being lower than those living with others, the differences were small, and not statistically significant [48]. However, satisfaction with life was significantly lower for all those living alone and for those living alone with low support, reflecting a small but consistent effect. This highlights the value of considering a range of indices that reflect aspects of 'living well'; although there is measurement overlap between the different constructs of quality of life, well-being, and satisfaction with life, they are not equivalent $[17,48]$. The finding of differences in satisfaction with life may reflect the experience of a 'vague existence' [10] described in qualitative studies, with practical difficulties leading to a lack of meaning and purpose in life [10-12]. Consideration could be given to ways of enabling those living alone with dementia to have a more satisfying experience. Given the heterogeneity among this group, a personalized approach seems most likely to be effective.

Regarding service use, the findings in the current study suggest a general pattern of higher use of homebased services. As might be expected, those living alone with dementia were more likely to use domestic help and equipment than those living with others 
because there was no-one else in the household to assist with activities of daily living.

A limitation of the study may be the sampling strategy whereby participants were recruited mainly from among those attending NHS services. It was not possible to include people living with dementia who have not been formally diagnosed. Caregivers, especially spouses, might encourage participation, while people with no caregiver may be less likely either to be approached or to join the study. However, we did explicitly encourage recruitment of those with no caregiver, including those living alone, as we did not want to exclude this group. The IDEAL cohort participants were $96 \%$ white British, and therefore our study does not address the situation of people from black and minority ethnic groups. Nevertheless, the findings are based on a large sample which is considered to represent the population attending NHS memory clinics in the UK reasonably well, and provides information about the broad range of social and psychological resources that influence ability to 'live well' with dementia. Although this was a large sample, making it feasible to compare those living alone and those living with others, the sub-group of individuals living alone with low support was small, and the limited range of statistically-significant effects may be attributable at least in part to the small numbers in this sub-group. This may be the case both for variables such as loneliness which did emerge as relevant for the whole group of people living alone and for variables such as social participation that did not show significant differences for the whole group of people living alone. It seems reasonable to assume that the psychological and social impact of dementia is extensive for all or at least the majority of participants irrespective of living situation, and additional differences relating to living situation may be relatively smaller and hard to detect. Further research with a larger sample of individuals living alone with limited support could yield more fine-grained analyses. Additionally, as IDEAL was an extensive survey, short versions of measures were used where possible to avoid over-burdening participants; it is possible that a more in-depth focus on specific areas of experience with more extensive measures might identify differences not found in our analyses. However, as the finding of no or only small differences is consistent across a range of measures, and the full score range was typically used, there is no particular reason to think that any individual measures are especially insensitive. Our findings are based on cross-sectional data and as IDEAL is a longitudinal study it will be possible in future to explore whether and at what point the experiences and needs of people living alone diverge from those living with others, and the influences on these trajectories over time.

\section{Conclusions}

People living alone with mild-to-moderate dementia constitute a sizeable group, and it is important to establish how their needs may best be met and how they may be supported to have a more satisfactory experience. The findings are consistent with the view that it is possible to 'live well' with mild-to-moderate dementia while living alone, given appropriate support. This may include support to reduce loneliness, maintain social engagement, and manage the impact of dementia symptoms on everyday life, including availability of home care and access to equipment such as memory and falls prevention aids. Consideration should be given to the best ways of ensuring that this kind of support is available. As patterns of service use differ according to living situation, consideration should also be given to ensuring that health and social care services are responsive to the particular needs of those living alone. It will be important to establish how the needs of this group change as dementia progresses and what additional support is required over time.

\section{ACKNOWLEDGMENTS}

'Improving the experience of Dementia and Enhancing Active Life: living well with dementia. The IDEAL study' was funded jointly by the Economic and Social Research Council (ESRC) and the National Institute for Health Research (NIHR) through grant ES/L001853/2. Investigators: L. Clare, I.R. Jones, C. Victor, J.V. Hindle, R.W. Jones, M. Knapp, M. Kopelman, R. Litherland, A. Martyr, F. Matthews, R.G. Morris, S.M. Nelis, J. Pickett, C. Quinn, J. Rusted, J. Thom. ESRC is part of UK Research and Innovation (UKRI). 'Improving the experience of Dementia and Enhancing Active Life: a longitudinal perspective on living well with dementia. The IDEAL-2 study' is funded by Alzheimer's Society, grant number 348, AS-PR2-16-001. Investigators: L. Clare, I.R. Jones, C. Victor, C. Ballard, A. Hillman, J.V. Hindle, J. Hughes, R.W. Jones, M. Knapp, R. Litherland, A. Martyr, F. Matthews, R.G. Morris, S.M. Nelis, C. Quinn, J. Rusted. The views expressed are those of the author(s) and not necessarily those of the ESRC, UKRI, NIHR, the Department 
of Health and Social Care, the National Health Service, or Alzheimer's Society. The support of ESRC, NIHR and Alzheimer's Society is gratefully acknowledged.

We would like to acknowledge the support of the following research networks: NIHR Dementias and neurodegeneration specialty (DeNDRoN) in England, the Scottish Dementia Clinical Research Network (SDCRN) and Health and Care Research Wales. We gratefully acknowledge the local principal investigators and researchers involved in participant recruitment and assessment within these networks. We thank the members of the ALWAYs group and the Project Advisory Group for their support with the study.

Authors' disclosures available online (https://www. j-alz.com/manuscript-disclosures/20-0638r1).

\section{DATA AVAILABILITY}

IDEAL data were deposited with the UK data archive in April 2020 and will be available for access from April 2023. Details of how the data can be accessed after that date can be found here: https:// reshare.ukdataservice.ac.uk/854293/.

\section{SUPPLEMENTARY MATERIAL}

The supplementary material is available in the electronic version of this article: https://dx.doi.org/ 10.3233/JAD200638.

\section{REFERENCES}

[1] Office for National Statistics, Families and households in the UK. 2017, https://www.ons.gov.uk/peoplepopulation andcommunity/birthsdeathsandmarriages/families/bulletins /familiesandhouseholds/2017

[2] Kolanowski A, Fortinsky RH, Calkins M, Devanand DP, Gould E, Heller T, Hodgson NA, Kales HC, Kaye J, Lyketsos C, Resnick B, Schicker M, Zimmerman S (2018) Advancing research on care needs and supportive approaches for persons with dementia: Recommendations and rationale. J Am Med Dir Assoc 19, 1047-1053.

[3] Nourhashemi F, Amouyal-Barkate K, Gillette-Guyonnet S, Cantet C, Vellas B (2005) Living alone with Alzheimer's disease: Cross-sectional and longitudinal analysis in the REAL.FR Study. J Nutr Health Aging 9, 117-120.

[4] Eichler T, Hoffmann W, Hertel J, Richter S, Wucherer D, Michalowsky B, Dreier A, Thyrian JR (2016) Living alone with dementia: Prevalence, correlates and the utilization of health and nursing care services. J Alzheimers Dis 52, 619-629.

[5] Webber PA, Fox P, Burnette D (1994) Living alone with Alzheimer's disease: Effects on health and social service utilization patterns. Gerontologist 34, 8-14.
[6] Ebly EM, Hogan DB, Rockwood K (1999) Living alone with dementia. Dement Geriatr Cogn Disord 10, 541-548.

[7] Habermann S, Cooper C, Katona C, Livingston G (2009) Predictors of entering 24-h care for people with Alzheimer's disease: Results from the LASER-AD study. Int J Geriatr Psychiatry 24, 1291-1298.

[8] Miranda-Castillo C, Woods B, Orrell M (2010) People with dementia living alone: What are their needs and what kind of support are they receiving? Int Psychogeriatr 22, 607-617.

[9] Charles J, Naglie G, Lee J, Moineddin R, Jaglal S, Tierney MC (2015) Self-report measures of well-being predict incident harm due to self-neglect in cognitively impaired seniors who live alone. J Alzheimers Dis 44, 425-430.

[10] Svanström R, Sundler AJ (2015) Gradually losing one's foothold-a fragmented existence when living alone with dementia. Dementia 14, 145-163.

[11] Lloyd BT, Stirling C (2015) The will to mobility: Life-space satisfaction and distress in people with dementia who live alone. Ageing Soc 35, 1801-1820.

[12] Duane F, Brasher K, Koch S (2013) Living alone with dementia. Dementia 12, 123-136.

[13] Frazer SM, Oyebode JR, Cleary A (2011) How older women who live alone with dementia make sense of their experiences: An interpretative phenomenological analysis. Dementia 11, 677-693.

[14] Clare L, Nelis SM, Quinn C, Martyr A, Henderson C, Hindle JV, Jones IR, Jones RW, Knapp M, Kopelman MD, Morris RG, Pickett JA, Rusted JM, Savitch NM, Thom JM, Victor CR (2014) Improving the experience of dementia and enhancing active life - living well with dementia: Study protocol for the IDEAL study. Health Qual Life Outcomes 12, 164

[15] Silarova B, Nelis SM, Ashworth RM, Ballard C, Bieńkiewicz M, Henderson C, Hillman A, Hindle JV, Hughes JC, Lamont RA, Litherland R, Jones IR, Jones RW, Knapp M, Kotting P, Martyr A, Matthews FE, Morris RG, Quinn C, Regan J, Rusted JM, van den Heuvel EA, Victor CR, Wu Y-T, Clare L (2018) Protocol for the IDEAL-2 longitudinal study: Following the experiences of people with dementia and their primary carers to understand what contributes to living well with dementia and enhances active life. BMC Public Health 18, 1214.

[16] Folstein MF, Folstein SE, McHugh PR (1975) "Mini-mental state". A practical method for grading the cognitive state of patients for the clinician. J Psychiatr Res 12, 189-198.

[17] Clare L, Wu Y-T, Jones IR, Victor CR, Nelis SM, Martyr A, Quinn C, Litherland R, Pickett JA, Hindle JV, Jones RW, Knapp M, Kopelman MD, Morris RG, Rusted JM, Thom JM, Lamont RA, Henderson C, Rippon I, Hillman A, Matthews FE, On behalf of the IDEAL study team (2019) A comprehensive model of factors associated with subjective perceptions of "living well" with dementia: Findings from the IDEAL study. Alzheimer Dis Assoc Disord 33, 36-41.

[18] Clare L, Wu Y-T, Quinn C, Jones IR, Victor CR, Nelis SM, Martyr A, Litherland R, Pickett JA, Hindle JV, Jones RW, Knapp M, Kopelman MD, Morris RG, Rusted JM, Thom JM, Lamont RA, Henderson C, Rippon I, Hillman A, Matthews FE, On behalf of the IDEAL study team (2019) A comprehensive model of factors associated with capability to "live well" for family caregivers of people living with mild-to-moderate dementia: Findings from the IDEAL study. Alzheimer Dis Assoc Disord 33, 29-35.

[19] Office for National Statistics (2010) Standard Occupational Classification 2010. Volume 3. The National Statistics 
Socio-economic Classification: (Rebased on the SOC2010)

User Manual, Palgrave Macmillan, Basingstoke.

[20] Charlson ME, Charlson RE, Peterson JC, Marinopoulos SS, Briggs WM, Hollenberg JP (2008) The Charlson comorbidity index is adapted to predict costs of chronic disease in primary care patients. J Clin Epidemiol 61, 1234-1240.

[21] Charlson ME, Pompei P, Ales KL, MacKenzie CR (1987) A new method of classifying prognostic comorbidity in longitudinal studies: Development and validation. J Chronic Dis 40, 373-383.

[22] Bowling A (2005) Just one question: If one question works, why ask several? J Epidemiol Community Health 59, 342-345.

[23] Hsieh S, Schubert S, Hoon C, Mioshi E, Hodges JR (2013) Validation of the Addenbrooke's Cognitive Examination III in frontotemporal dementia and Alzheimer's disease. Dement Geriatr Cogn Disord 36, 242-250.

[24] Brickman AM, Riba A, Bell K, Marder K, Albert M, Brandt J, Stern Y (2002) Longitudinal assessment of patient dependence in Alzheimer disease. Arch Neurol 59, 1304-1308.

[25] Martyr A, Clare L, Nelis SM, Marková IS, Roth I, Woods RT, Whitaker CJ, Morris RG (2012) Verbal fluency and awareness of functional deficits in early-stage dementia. Clin Neuropsychol 26, 501-519.

[26] Pfeffer RI, Kurosaki TT, Harrah CH, Jr., Chance JM, Filos S (1982) Measurement of functional activities in older adults in the community. J Gerontol 37, 323-329.

[27] Almeida OP, Almeida SA (1999) Short versions of the Geriatric Depression Scale: A study of their validity for the diagnosis of a major depressive episode according to ICD-10 and DSM-IV. Int J Geriatr Psychiatry 14, 858-865.

[28] Wu Y-T, Clare L, Matthews FE, on behalf of the Improving the experience of Dementia and Enhancing Active Life (IDEAL) study team (2019) Relationship between depressive symptoms and capability to live well in people with dementia and their carers: Results from the Improving the experience of Dementia and Enhancing Active Life (IDEAL) programme. Aging Ment Health, doi: 10.1080/13607863.2019.1671316

[29] Kaufer DI, Cummings JL, Ketchel P, Smith V, MacMillan A, Shelley T, Lopez OL, DeKosky ST (2000) Validation of the NPI-Q, a brief clinical form of the Neuropsychiatric Inventory. J Neuropsychiatry Clin Neurosci 12, 233-239.

[30] Morris JC, National Alzheimer's Coordinating Center (2008) NACC Uniform Data Set (UDS) Coding Guidebook for Initial Visit Packet, National Institute on Aging, ADC Clinical Task Force, NACC, University of Washington, Seattle.

[31] Rosenberg M (1965) Society and the adolescent self-image, Princeton University Press, Princeton, NJ.

[32] Schwarzer R, Jerusalem M (1995) Generalized self-efficacy scale. In Measures in health psychology: A user's portfolio. Causal and control beliefs, Weinman J, Wright S, Johnston M, eds. NFER-NELSON, Windsor, UK, pp. 35-37.

[33] Scheier MF, Carver CS, Bridges MW (1994) Distinguishing optimism from neuroticism (and trait anxiety, self-mastery, and self-esteem): A reevaluation of the Life Orientation Test. J Pers Soc Psychol 67, 1063-1078.

[34] De Jong Gierveld J, Van Tilburg TG (2006) A 6-item scale for overall, emotional, and social loneliness confirmatory tests on survey data. Res Aging 28, 582-598.
[35] De Jong Gierveld J, Van Tilburg TG, Manual of the Loneliness Scale, Retrieved from Vrije Universiteit Amsterdam website: https://home.fsw.vu.nl/tg.van.tilburg/manual_ loneliness_scale_1999.html.

[36] Victor CR, Rippon I, Nelis SM, Martyr A, Litherland R, Pickett JA, Hart N, Henley J, Matthews FE, Clare L, on behalf of the IDEAL programme team (2020) Prevalence and determinants of loneliness in people living with dementia: Findings from the IDEAL programme. Int J Geriatr Psychiatry 35, 851-858.

[37] Burgener SC, Berger B (2008) Measuring perceived stigma in persons with progressive neurological disease: Alzheimer's dementia and Parkinson's disease. Dementia 7, 31-53.

[38] Quinn C, Morris RG, Clare L (2018) Beliefs about dementia: Development and validation of the Representations and Adjustment to Dementia Index (RADIX). Am J Geriatr Psychiatry 26, 680-689.

[39] Lubben J, Blozik E, Gillmann G, Iliffe S, von Renteln Kruse W, Beck JC, Stuck AE (2006) Performance of an abbreviated version of the Lubben Social Network Scale among three European community-dwelling older adult populations. Gerontologist 46, 503-513.

[40] Webber MP, Huxley PJ (2007) Measuring access to social capital: The validity and reliability of the Resource Generator-UK and its association with common mental disorder. Social Sci Med 65, 481-492.

[41] Office for National Statistics (2008) Harmonised concepts and questions for social data sources, secondary standards. Social capital, Office for National Statistics, Titchfield, UK.

[42] Thomson K (2004) Cultural capital and social exclusion survey: Technical report, National Centre for Social Research, London.

[43] Logsdon RG, Gibbons LE, McCurry SM, Teri L (2000) Quality of life in Alzheimer's disease: Patient and caregiver reports. In Assessing quality of life in dementia, Albert SM, Logsdon RG, eds. Springer, New York, pp. 17-30.

[44] Diener E, Emmons RA, Larsen RJ, Griffin S (1985) The Satisfaction with Life Scale. J Pers Assess 49, 71-75.

[45] Bech P (2004) Measuring the dimension of psychological general well-being by the WHO-5. Qual Life Newsletter 32, 15-16.

[46] Henderson C, Knapp M, Nelis SM, Quinn C, Martyr A, Wu Y-T, Jones IR, Victor CR, Pickett JA, Hindle JV, Jones RW, Kopelman MD, Matthews FE, Morris RG, Rusted J, Thom JM, Clare L, on behalf of the IDEAL programme team (2019) Use and costs of services and unpaid care for people with mild-to-moderate dementia: Baseline results from the IDEAL cohort study. Alzheimers Dement (N Y) 5, 685-696.

[47] Lehmann SW, Black BS, Shore A, Kasper J, Rabins PV (2010) Living alone with dementia: Lack of awareness adds to functional and cognitive vulnerabilities. Int Psychogeriatr 22, 778-784.

[48] Martyr A, Nelis SM, Quinn C, Wu Y-T, Lamont RA, Henderson C, Clarke R, Hindle JV, Thom JM, Jones IR, Morris RG, Rusted JM, Victor CR, Clare L (2018) Living well with dementia: A systematic review and correlational metaanalysis of factors associated with quality of life, well-being and life satisfaction in people with dementia. Psychol Med 48, 2130-2139. 